\title{
The Demand for Intercity Public Transport: The Case of Business Passengers
}

\author{
Fredrik Carlsson \\ Working Papers in Economics no 12 \\ March 1999 \\ Department of Economics \\ Göteborg University
}

\begin{abstract}
Using a stated preference survey on business passengers travelling with rail or air between the two largest cities in Sweden, we investigate business passengers' preferences for different modes of transport and their corresponding attributes. We explore the usefulness of a more flexible specification of the demand for transport by using a random parameter logit (RPL) model. In the paper we find that there is a gain in using an RPL model compared to a fixed effect model, in the sense that it provides richer information about the passengers' preferences. However, we also find that the valuation of attributes does not significantly differ between a standard logit and an RPL model. Compared to what previous studies have found, the values put on attributes are very high, this including the environmental impact of the modes. This is largely explained by the fact that business passengers do not bear the cost of the trip, but still have the possibility if deciding mode of transport.
\end{abstract}

Keywords: Business passengers, Intercity transport, Random parameter logit.

JEL-classification: C25, R41.

Department of Economics

Göteborg University

Box 640

SE-40530 Göteborg

Sweden

Tel: +46 317734174

Fax: +46 317731043

e-mail: Fredrik.Carlsson@economics.gu.se 


\section{Introduction ${ }^{1}$}

In this paper we use an econometric model, random parameter logit, in the analysis of stated preference (SP) data that allows for heterogeneous preferences. The model also makes use of the fact that respondents make repeated choices in SP surveys. There are a large number of stated preference (SP) and revealed preference (RP) studies of passengers' preferences for intercity transport. Traditionally, logit or binary probit models have been used using only SP data (see e.g. Hensher 1994 and Polak and Jones 1997) or using both SP and RP data (e.g. Ben-Akiva \& Morikawa 1990, Bradley and Daly 1997). There are of course several advantages of using these simple specifications, most notably the simplicity of estimation. However, these models impose some serious restrictions. More recently, heteroskedastic (Bhat 1995, Hensher and King 1998) and covariance heterogeneity specifications (Bhat 1997) have been used in order to reduce the influence of these restrictions. Another class of less restrictive models are random parameter models. These models are by no means new, but they have been burdensome to estimate as they are computer intensive. With increasing computer capacity and better simulation methods there has been an increasing use of this type of model in the analysis of transport demand. In this paper we analyse a SP survey on business passengers travelling by rail or air between Stockholm and Gothenburg in Sweden. Business passengers are a group with some distinctive characteristics as compared to non-business passengers, and therefore some additional aspects will be considered in the paper.

The objective of this paper is to compare a more flexible econometric model with a standard logit model when analysing passengers' choice of mode, and their valuation of attributes. Further, we wish to investigate business passengers' preferences for different modes, and the corresponding attributes. Of particular interest is to investigate whether the environmental impact of the transport mode affects the passengers' choice.

The paper is organised in the following way. In Section 2 we describe the econometric models used for the analysis of the passengers' choice of mode. In Section 3 , the SP survey is described. In Section 4 we present and discuss the results.

\footnotetext{
${ }^{1}$ The author would like to thank Gardner Brown, Peter Frykblom, Olof Johansson-Stenman Mattias Lundbäck, and Peter Martinsson for useful comments. Financial support from the Swedish Civil Aviation Administration is gratefully acknowledged.
} 


\section{The Econometrics of Mode Choice}

Traditionally the analysis of SP and RP data has been based on rather restrictive econometric specifications. In order to clarify the restrictions, we start with the standard random utility theory (McFadden 1974) where we define an unobserved, latent, individual utility function of alternative $i$ for individual $q$, consisting of a systematic part and a stochastic part:

$$
U_{i q}=V_{i q}+\varepsilon_{i q}=\beta x_{i q}+\varepsilon_{i q}
$$

where $x_{i q}$ is a vector of alternative specific attributes. The choice probability for alternative $i$ is equal to the probability that the utility is greater than or equal to the utilities of all other alternatives in the choice set, $\mathbf{A}=\left\{A_{1}, \ldots, A_{N}\right\}$ :

$$
P_{q}(i \mid \beta)=P\left(\varepsilon_{j q} \leq \varepsilon_{i q}+V_{i q}-V_{j q} ; \forall j \in \mathbf{A}\right) .
$$

If we assume that the error terms are independently and identically distributed (IID) type I extreme value, with scale parameter $\mu$, the choice probability is:

$$
P_{q}(i \mid \beta)=\frac{\exp \left(\mu V_{i q}\right)}{\sum_{j \in \mathbf{A}} \exp \left(\mu V_{j q}\right)}=\frac{\exp \left(\mu \beta x_{i q}\right)}{\sum_{j \in \mathbf{A}} \exp \left(\mu \beta x_{j q}\right)},
$$

which is the standard multinomial logit model. Notably there are two important problems with this specification (i) the alternatives are independent, and (ii) there is no taste variation among respondents. The first problem arises because of the IID assumption, which results in the independence of irrelevant alternatives (IIA) property. The influence of the IIA property can be reduced by specifying a nested structure, where we do not have the IIA property between nests, but within nests. An alternative specification is to assume that error terms are independently, but non-identically, distributed type I extreme value, with scale parameter $\mu_{i}$ (Allenby and Ginter 1995, Bhat 1995). This would allow for different cross elasticities among all pairs of alternatives, i.e. relaxing the IIA restriction. We could also model heterogeneity in the 
covariance among nested alternatives (Bhat 1997). In this paper we explore another class of models where tastes are allowed to vary in the population, i.e. random parameter models. This is in no way a novelty since Hausman and Wise (1978) were the first to use a random effects probit model on transport demand. Until now, the problem has been that the models are burdensome to estimate, but the development of simulation methods and computing power have made it possible to estimate them more easily. In order to illustrate this type of model, let us write the utility function of alternative $i$ for individual $q$ as:

$$
U_{i q}=\beta x_{i q}+\varepsilon_{i q}=\bar{\beta} x_{i q}+\widetilde{\beta}_{q} x_{i q}+\varepsilon_{i q} .
$$

Thus, each individual's coefficient vector $\beta$ is the sum of the population mean $\bar{\beta}$ and individual deviation $\widetilde{\beta}_{q}$. The stochastic part of utility, $\widetilde{\beta}_{q} x_{i q}+\varepsilon_{i q}$, is correlated over alternatives, which means that the model does not exhibit the IIA property. Let tastes, $\beta$, vary in the population with a distribution with density $f(\beta \mid \theta)$, where $\theta$ is a vector of the true parameters of the taste distribution. If $\beta$ is distributed normal and the $\varepsilon ' s$ are IID standard normal we have a random parameter multinomial probit model. ${ }^{2}$ If instead the $\varepsilon$ 's are IID type I extreme value, we have what is usually called a random parameter logit (RPL) model, introduced by Boyd and Mellman (1980) and Cardell and Dunbar (1980). The unconditional probability of alternative $i$ for individual $q$ can then be expressed as the integral of the conditional probability in (3) over all values of $\beta$ :

$$
P_{q}(i \mid \theta)=\int P_{q}(i \mid \beta) f(\beta \mid \theta) d \beta=\int \frac{\exp \left(\mu \beta x_{i q}\right)}{\sum_{j \in \mathbf{A}} \exp \left(\mu \beta x_{j q}\right)} f(\beta \mid \theta) d \beta
$$

Furthermore, the econometric model should use the fact that respondents make repeated choices in the SP survey. Earlier, this has resulted in application of binary logit or probit models for panel data. However, the estimator used in this paper can also be extended to panel data with multinomial choices (Revelt and Train 1999, Train 1998). In order to

\footnotetext{
${ }^{2}$ For a recent application of this type of model see Chen and Cosslett (1998).
} 
extend the analysis to panel data, let us write the conditional probability that alternative $i$ is chosen in choice situation $t$ as:

$$
P_{q}(i t \mid \beta)=\frac{\exp \left(\mu \beta x_{i q t}\right)}{\sum_{j \in \mathbf{A}_{t}} \exp \left(\mu \beta x_{j q t}\right)}
$$

Consequently, the conditional probability of observing a sequence of choices, denoted $j(q, t)$, from the choice sets is the product of standard logit probabilities:

$$
S_{q}(\beta)=\prod_{t} P(j(q, t) t \mid \beta)
$$

In the SP case, the sequence of choices is the number of hypothetical choices each respondent makes in a survey. The unconditional probability for a sequence of choices for individual $q$ is then the integral of the conditional probability in (7) over all values of $\beta$ :

$$
P_{q}(\theta)=\int S_{q}(\beta) f(\beta \mid \theta) d \beta
$$

In general the integrals in (5) and (8) cannot be evaluated analytically, and we have to rely on a simulation method for the probabilities. For a general discussion of simulation methods for limited dependent models see Hajivassiliou (1993). Here we will use a simulated maximum likelihood estimator to estimate the models, see e.g. Brownstone and Train (1996) for the cross-section model in (5), and Revelt and Train (1999) and Train (1998) for the panel-data model in (8). ${ }^{3}$ When estimating these types of models we have to assume a distribution for each of the random coefficients. For comparative reasons we will estimate three models: a standard logit model with fixed parameters, an RPL model with independently normally distributed coefficients, and an RPL model

\footnotetext{
${ }^{3}$ In brief the simulator can be described as follows. From a given distribution $\theta$, individual specific values of $\beta$ are drawn. From these draws we approximate the choice probability using the standard logit. The average of $Z$ such draws is the approximate choice probability for individual $\mathrm{q}$, denoted $S P_{q}=(1 / Z) \sum_{r=1}^{Z} S_{q}\left(\beta_{r}\right)$. The simulated log likelihood is then $S L L=\sum_{n} \ln \left(S P_{n}\right)$, where subscript $\mathrm{n}$ index sampled individuals.
} 
with normally distributed coefficients but correlation over the coefficients. If the coefficients are independently normally distributed, the coefficient vector can be written $\beta_{q}=\bar{\beta}+Q \eta_{q}$, where $\mathrm{Q}$ is a diagonal matrix of standard deviations, with elements of zeros for the fixed coefficients, and $\eta_{q}$ is a vector of independent standard normal deviates. The coefficients $\bar{\beta}$ and $Q$, representing the mean and standard deviation of $\beta_{q}$, are estimated. If the coefficients are normally distributed and correlated, i.e. $\beta_{q} \sim N(\bar{\beta}, \Omega)$, with preference variance-covariance matrix $\Omega$, the coefficient vector is written $\beta_{q}=\bar{\beta}+C \eta_{q}$. Here $\bar{\beta}$ and $C$ are estimated, where $\mathrm{C}$ is the lower triangular Cholesky factor of the preference variance-covariance matrix $\Omega$, i.e. $\Omega=C^{\prime}$ '. For both RPL models in this paper we thus assume that the random parameters are normally distributed. ${ }^{4}$

The RPL model has a very interesting property. McFadden and Train (1998) show that under some mild regularity conditions any discrete choice model derived from random utility maximisation has choice probabilities that can be approximated by an RPL model. This is interesting, because RPL models can then be used to approximate difficult parametric random utility models such as the multinomial probit model, by taking the distributions underlying these models as the parameter distributions.

\footnotetext{
${ }^{4} \mathrm{~A}$ log-normal distribution is in fact more appropriate when we wish to restrict a coefficient to be either positive or negative. However, it is in general more difficult to have a converging model using a lognormal distribution and the software we use for the correlation model does not allow us to specify a lognormal distribution.
} 


\section{The SP Survey}

\subsection{Business Passengers}

The goal of our SP survey was to investigate the business passenger's choice between rail and air when travelling between Gothenburg and Stockholm. Of particular interest was to investigate whether the environmental impact of the modes is of any importance for the choice of mode. For business passengers there are some important aspects that we must consider. There is a mix of individual and organisational incentives involved in planning the journey for business travels. The two extreme cases are either that the company dictates the trip exactly, or that the company lets the individual fully plan the trip. We will call the type of planning the "delegation mechanism". The analysis in itself does not differ between types of travellers, but we must be aware that we are measuring a mixture of preferences in the case of business passengers. For example, if the travellers do not have to bear any cost of the trip, they might still take the cost into consideration when making their decisions (see e.g. Fowkes et al. 1991). Thus, the delegation mechanism will become important for the analysis of the passenger's choice, as it may affect the passenger's valuation of the attributes, e.g. that the price attribute becomes less important. It is important to note that both extreme types of delegation mechanisms can be optimal for the principal, depending on the situation. Hence we cannot say that one mechanism is more efficient than the other without further information. However, what we can do is to speculate when different mechanisms are likely to occur and how these will affect the choice of mode and the value put on attributes. Aghion and Tirole (1997) discuss the allocation of what they call formal authority (the right to decide) and real authority (the effective control over decisions) within organisations. They show that delegation to subordinates is more likely to occur when the decisions are relatively unimportant to the principal, when the principal can trust the agent, and when the decisions are important for the agent. For business passengers we might expect that it is more likely that the decision about the trip is delegated to the passengers, especially for frequent travellers since this is of great importance to the traveller. At the same time the delegation will involve a costly loss of control for the principal. In the case of business trips the delegation would involve a 
more lax budget restriction, since the trips have no direct effect on the subordinate's own budget. We therefore expect the value put on the attributes to be larger for business passengers compared with non-business passengers. At the same time the estimated values should be interpreted with care, since the influence of the principal's preferences are reduced in the survey. However, the estimated values could still be interpreted as the business passengers' preferences over the attributes.

\subsection{Experiment and Design}

There are several decisions to be made when designing experiments. First of all, we must determine which attributes to include in the experiment and the levels of each attribute. This is based on extensive qualitative research, including a pilot study. Apart from what we call the primary attributes, price and travel time, we decided to investigate the impact of several secondary attributes. ${ }^{5}$ These secondary attributes are environmental impact, reliability and comfort. For rail travel, environmental impact is the share of so called 'green electricity' that is used, reliability is the share of departures that are not more than 10 minutes late on arrival, and comfort is the passenger space. For air travel, the environmental impact is the amount of emissions per flight, reliability is the share of departures that are not more than 5 minutes late on arrival, and comfort is the passenger space. Constructing a choice experiment with five or six attributes where each attribute has two to three levels is difficult, especially if we wish to allow for interaction-effects between the attributes. Further, it may be cognitively demanding for the respondent to answer such complex questions. It might also be difficult to make trade-offs between primary and secondary attributes, since the magnitude of the partworth utilities are very different. Therefore we used a hierarchical design, where attributes are grouped into subsets of primary and secondary attributes (see e.g. Louviere 1984, Louviere and Timmermans 1990) We created secondary experiments for each mode, and both experiments were answered by all passengers. Each respondent was asked to rank six sets of four 2-level attributes: environment, reliability, comfort and increased price.

\footnotetext{
${ }^{5}$ The labelling of the attributes is more or less arbitrary. Further, what are primary attributes for some respondents, others might regard as completely irrelevant.
} 
It would have been possible to use the full factorial design of eight sets, but based on experiences from the pilot study the two dominating sets were excluded. The respondents were informed that there are several possible improvements of the modes, and that they were asked to rank different combinations of improvements, where each package would result in a specific increase in the price. The attributes and the levels are presented in Table A1 in the Appendix.

The primary experiment was a choice experiment with four alternatives: IC-train, X2000-train, Air Arlanda, and Air Bromma. ${ }^{6}$ Each alternative was described by three attributes: price, travel time and a composite factor. The attributes and their levels are presented in Table A2 in the Appendix. The composite factor consisted of the three attributes from the secondary experiments: environment, reliability and comfort. If the composite factor is on then all improvements are included, and when the composite factor is off none of the improvements are included. Travel time for air travel included the transfer from the city centre to the airport, while rail travel only included onboard time. Time and the composite factor were both 2-level attributes while price was a 3level attribute; there were thus $3^{4} 2^{8}$ combinations of attribute levels, since there are four alternatives in each set. From a resolution IV-design, ${ }^{7}$ which consists of 432 sets, we created a D-efficient design with 60 sets using the OPTEX routine in SAS. These sets were then blocked into 10 subsets. Consequently each respondent made six choice exercises in the primary experiment. The respondents were asked to answer the question given the circumstances of the trip that they were presently undertaking. The main reason for this was to ensure that business passengers would answer the survey as business passengers and not as private passengers.

The hierarchical design allowed us to introduce several attributes in the experiment, but not all at once. This reduced the cognitive burden for the respondents. In order to reduce the risk of fatigue we used the same attributes in the air and train experiment, although there might have been other attributes of importance for one of the modes.

\footnotetext{
${ }^{6}$ The IC-train is an old and slower type of train and the X2000-train is a new and faster type. Arlanda and Bromma are the two airports in Stockholm.

${ }^{7}$ With a resolution IV-design all main effects are estimable free of each other and all two-factor interactions.
} 
In order to illustrate the hierarchical model, let us write the utility function for mode $i$ for the primary and the secondary experiment respectively as:

$$
\begin{aligned}
U_{i} & =\alpha_{i}+\beta_{1 i} \text { Fare }_{i}+\beta_{2 i} \text { Time }_{i}+\beta_{3 i} C_{i}, \\
u_{i} & =\gamma_{1 i} y_{1 i}+\gamma_{2 i} y_{2 i}+\gamma_{3 i} y_{3 i}+\gamma_{4 i} \text { Fare }_{i}
\end{aligned}
$$

where $C_{i q}$ is the composite good, and $y_{j}$ is the $\mathrm{j}$ :th attribute in the secondary experiment. From the utility functions we obtain fare equivalencies for the composite goods in the primary experiment, and for each of the attributes in the secondary experiments as:

$$
\begin{gathered}
\text { Fare-equivalent } \mathrm{C}_{i}=\frac{\partial U_{i} / \partial C_{i}}{\partial U_{i} / \partial \text { Fare }_{i}}=\frac{\beta_{3 i}}{\beta_{1 i}} \\
\text { Fare - equivalent } y_{j i}=\frac{\partial u_{i} / \partial y_{j i}}{\partial u_{i} / \partial \text { Fare }_{\mathrm{i}}}=\frac{\gamma_{\mathrm{ji}}}{\gamma_{4 \mathrm{i}}}
\end{gathered}
$$

If there were no interaction effects between any of the attributes in the secondary experiment we would expect that the sum of the fare-equivalents from the secondary experiments is at least as large as the corresponding fare equivalent for the composite good.

In this survey we use the hierarchical design to introduce several primary and secondary attributes in a convenient way. The secondary experiments were ranking exercises and they did not include the option to not choose any of the alternatives. Thus, we might interpret these exercises as tools to gain information about the relative value of each attribute. Further, in that part of the experiment we only distinguished between rail and air travel, and not between different types within each mode. In the primary experiment, the respondents chose the preferred mode given the circumstances for the trip that they were undertaking at that moment. We therefore expect that the information given in that experiment better reflects the true valuation of the attributes. However in that part of the experiment each of the secondary attributes were not valued on its own, and it is therefore difficult to say anything about their individual values from that experiment. An alternative is to use the information about their relative values from the secondary experiments, and decompose the fare equivalent for the composite factor. 


\subsection{Sampling Strategy}

A number of rail passengers were approached on the trains. The questionnaires were handed out during the trip, and collected at the end of the trip. Before the questionnaire was delivered we did not know if the respondent was travelling between Stockholm and Gothenburg, or if he/she was a business passenger. In total 270 surveys were handed out, and 245 were returned. Of these 173 were answered by business passengers travelling between Stockholm and Gothenburg. A number of air passengers were approached at the airport after they had checked in, while they were waiting to board. From the pilot studies we had learned that it was not possible to let respondents answer the questionnaire at the airport since we would lose a large fraction of respondents checking in very late. Therefore we chose to use a mail survey for the air passengers. We covered all departures from Gothenburg in a one-week period. ${ }^{8}$ In total 700 mail surveys were handed out, and 382 responded. Of these, 322 were answered by business passengers travelling between Stockholm and Gothenburg. A number of respondents refused to participate at all. The non-response rate varied between departures and days, but roughly 10 percent refused to participate.

\footnotetext{
${ }^{8}$ The sampling strategy was to select as many passengers as possible from each flight. The problem with this strategy is that it is not purely random because while approaching one passenger, the following passengers might not be selected since the questionnaire was handed out immediately after the passengers checked in.
} 


\section{Analysis}

\subsection{Descriptive Statistics}

Table 1 reports the descriptive statistics of the respondents used in the final estimations.

Table 1. Descriptive statistics observations included in final estimations: whole sample and market segments.

\begin{tabular}{|c|c|c|c|c|c|c|}
\hline \multirow{2}{*}{ Variable } & \multicolumn{2}{|c|}{ Total sample } & \multicolumn{2}{|c|}{ Rail passengers } & \multicolumn{2}{|c|}{ Air passengers } \\
\hline & $\begin{array}{l}\text { Mean } \\
\text { (std.) }\end{array}$ & $\begin{array}{l}\text { Nobs } \\
\text { (freq.) }\end{array}$ & $\begin{array}{l}\text { Mean } \\
\text { (std.) }\end{array}$ & $\begin{array}{l}\text { Nobs } \\
\text { (freq.) }\end{array}$ & $\begin{array}{l}\text { Mean } \\
\text { (std.) }\end{array}$ & $\begin{array}{l}\text { Nobs } \\
\text { (freq.) }\end{array}$ \\
\hline \multicolumn{7}{|c|}{ Ticket price in SEK: ${ }^{9}$} \\
\hline - Single & $1004(558)$ & $116(25 \%)$ & $683(255)$ & $73(46 \%)$ & $1547(510)$ & $43(14 \%)$ \\
\hline - Roundtrip & 2694 (1254) & $341(75 \%)$ & $1483(453)$ & $85(54 \%)$ & 3096 (1174) & $256(86 \%)$ \\
\hline \multicolumn{7}{|l|}{ No. of trips last year: } \\
\hline - Air & $8.8(12.7)$ & $403(81 \%)$ & $2.2(4.3)$ & $83(48 \%)$ & $12.4(14.3)$ & $322(100 \%)$ \\
\hline - Bus & $0.02(0.2)$ & $10(2 \%)$ & $0.03(0.2)$ & $6(3 \%)$ & $0.02(0.19)$ & $4(1 \%)$ \\
\hline - Car & $0.9(2.0)$ & $158(32 \%)$ & $0.9(2.2)$ & $51(29 \%)$ & $0.9(1.85)$ & $107(33 \%)$ \\
\hline - Train & $3.7(10.3)$ & $295(60 \%)$ & $7.9(15.8)$ & $173(100 \%)$ & $1.5(3.97)$ & $125(39 \%)$ \\
\hline \multicolumn{7}{|c|}{$\begin{array}{l}\text { Decision about the mode } \\
\text { for this trip: }\end{array}$} \\
\hline - Self & & $416(84 \%)$ & & $132(77 \%)$ & & $284(88 \%)$ \\
\hline - Boss & & $18(4 \%)$ & & $9(5 \%)$ & & $8(3 \%)$ \\
\hline - Department rules & & $7(1 \%)$ & & $5(3 \%)$ & & $2(1 \%)$ \\
\hline - Company rules & & $53(11 \%)$ & & $26(15 \%)$ & & $27(8 \%)$ \\
\hline \multicolumn{7}{|l|}{ Sex: } \\
\hline - Male & & $326(75 \%)$ & & $118(69 \%)$ & & $248(78 \%)$ \\
\hline - Female & & $125(25 \%)$ & & $54(31 \%)$ & & $71(22 \%)$ \\
\hline \multicolumn{7}{|l|}{ Home: } \\
\hline - Gothenburg area & & $270(55 \%)$ & & $116(68 \%)$ & & $154(48 \%)$ \\
\hline - Stockholm area & & $107(22 \%)$ & & $15(9 \%)$ & & $92(29 \%)$ \\
\hline - Other & & $113(23 \%)$ & & $40(23 \%)$ & & $73(23 \%)$ \\
\hline \multicolumn{7}{|l|}{ Mode: } \\
\hline - Arlanda & & $177(36 \%)$ & & & & \\
\hline - Bromma & & $145(29 \%)$ & & & & \\
\hline - Rail & & $133(35 \%)$ & & & & \\
\hline Age in years & $44.1(11.0)$ & & $43.0(11.3)$ & & $44.8(10.8)$ & \\
\hline
\end{tabular}

From Table 1 we see that for rail passengers, air is the second most used mode and vice versa for air passengers; thus, the modes are clearly substitutes. Further, many of the respondents travel frequently between Stockholm and Gothenburg. For example on average air passengers travel between Stockholm and Gothenburg once a month. The price the passengers pay is within the range of the prices used in the experiment. Most of the respondents made their decisions about the mode for this trip themselves, although a non-negligible fraction exists who are governed by rules at their company. More than $50 \%$ of the passengers are from the Gothenburg area.

\footnotetext{
${ }^{9}$ US\$ 1 corresponds to 8 SEK in November 1998.
} 


\subsection{Econometric Analysis}

For the secondary experiment we use a standard logit model to estimate the parameters of the utility function, and the estimates are presented in Table 2.

Table 2. Estimations for ranking experiments, and fare equivalents in SEK.

\begin{tabular}{|c|c|c|c|c|}
\hline & \multicolumn{2}{|c|}{ Ranking Air } & \multicolumn{2}{|c|}{ Ranking Rail } \\
\hline & $\begin{array}{l}\text { Coefficient } \\
\text { (s.e) }\end{array}$ & $\begin{array}{l}\text { Fare equivalent } \\
\text { (s.e) }\end{array}$ & $\begin{array}{l}\text { Coefficient } \\
\text { (s.e.) }\end{array}$ & $\begin{array}{c}\text { Fare equivalent } \\
\text { (s.e.) }\end{array}$ \\
\hline Environment & $\begin{array}{r}1.517 \\
(0.093)\end{array}$ & $\begin{array}{r}291.35 \\
(75.25)\end{array}$ & $\begin{array}{r}0.930 \\
(0.069)\end{array}$ & $\begin{array}{r}122.06 \\
(21.07)\end{array}$ \\
\hline Reliability & $\begin{array}{r}0.892 \\
(0.087)\end{array}$ & $\begin{array}{c}171.35 \\
(36.82)\end{array}$ & $\begin{array}{r}1.083 \\
(0.064)\end{array}$ & $\begin{array}{c}142.21 \\
(26.68)\end{array}$ \\
\hline Comfort & $\begin{array}{r}0.353 \\
(0.092)\end{array}$ & $\begin{array}{r}67.75 \\
(8.27)\end{array}$ & $\begin{array}{r}0.229 \\
(0.070)\end{array}$ & $\begin{array}{r}31.07 \\
(5.86)\end{array}$ \\
\hline Cost & $\begin{array}{r}-0.005 \\
(0.001)\end{array}$ & & $\begin{array}{r}-0.008 \\
(0.002)\end{array}$ & \\
\hline Total fare eq. & & $\begin{array}{r}530.46 \\
(110.79)\end{array}$ & & $\begin{array}{l}294.34 \\
(44.85)\end{array}$ \\
\hline Log likelihood & 2864 & & 2857 & \\
\hline
\end{tabular}

Table 2 indicates that environmental impact is the most important attribute for air travels, while environmental impact and reliability are of equal importance for rail travels. Comfort is in both cases the least important attribute. The fare equivalents indicate for example that passengers are willing to pay 291 SEK per trip for reduced emissions from the aircraft. The total fare equivalent is larger for air travel; the main reason for this is the higher value put on the environmental impact of air transport. ${ }^{10}$ The distribution of the mean fare equivalent estimates is obtained with the KrinskyRobb method (Krinsky and Robb 1986) using 10,000 replications. Using this method we draw a number of times, from the asymptotic normal distribution of the parameter estimates, and calculate the fare equivalents for each of these draws. ${ }^{11}$

As we said in the Section 2, we will estimate three models for the primary experiment. For the RPL models we specify the price variable to be fixed for two

\footnotetext{
${ }^{10} \mathrm{We}$ also estimated fare equivalents for the segment air and train passengers but found no significant differences in fare equivalents.

${ }^{11}$ An alternative method is bootstrapping where we would create a number of new data sets using the estimated residuals, and re-estimate the function. The Krinsky-Robb method is of course less computationally burdensome. Further, for example Kling (1991) and Chen and Cosslett (1998) find that the two procedures give quite similar standard deviations. Since the Krinsky-Robb method require that the errors are asymptotically normal distributed, the comparison between this method and a bootstrapping procedure critically depends on the actual distribution of the errors.
} 
reasons: (i) the distribution of the marginal willingness-to-pay for an attribute is simply the distribution of that attribute's coefficient, and (ii) we wish to restrict the price variable to be non-positive for all individuals. The random coefficients are, beside the attributes in the experiment, three mode specific constants, an inertia variable for train passengers, ${ }^{12}$ and a dummy variable indicating that the respondent lives outside Gothenburg and Stockholm. In order to facilitate the simulations, price is scaled by 0.0001 , and time is scaled by 0.001 . We estimate all models using GAUSS. ${ }^{13}$ The results from the three estimations are presented in Table 3 below, and the preference variance-covariance matrix for the third model in Table A3 in the Appendix.

\footnotetext{
${ }^{12}$ It is interesting to note that the standard logit did not perform very well without inclusion of the inertia variable; the coefficient on time was positive for rail, although insignificant. Both RPL models give approximately the same result with and without inclusion of the inertia variable.

${ }^{13}$ The programs for GAUSS were kindly provided by Kenneth Train, University of California. The code can be downloaded from http://emlab.berkeley.edu/users/train/index.html.
} 
Table 3. Estimations for primary experiments Note that price variables are scaled by 0.0001 and time variables by scaled with 0.001 .

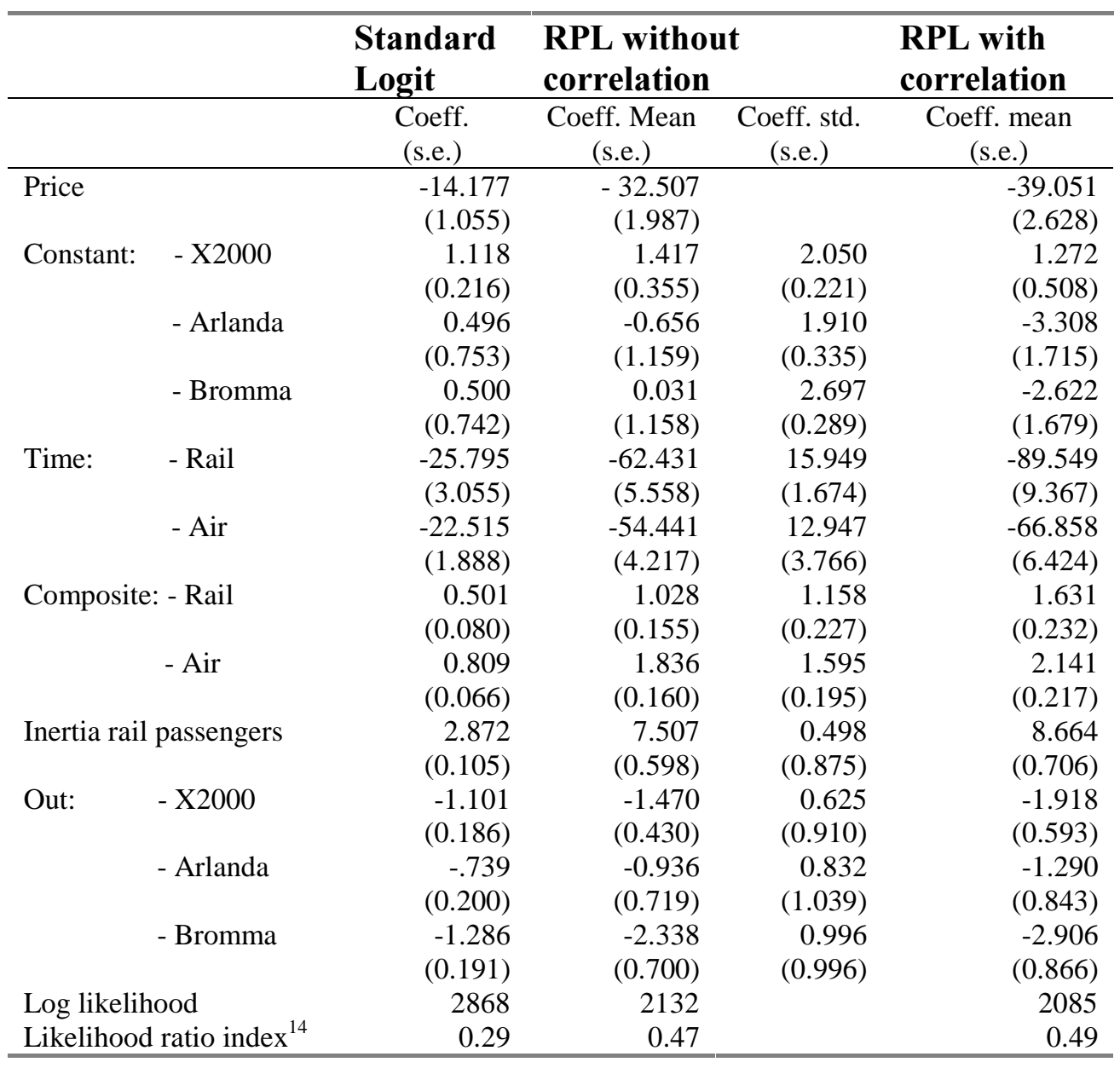

From Tables 3 and A3 we see that all coefficient and most of the estimated standard deviations are significant, indicating the presence of heterogeneity among the respondents. There is also a substantial increase in the likelihood ratio index compared with the fixed effect model. In the random model without correlation, all individual effects are highly significant, while in the model with correlation not all elements of the preference variance-covariance matrix are significant. Further the results indicate that the travel time and the composite variables are negatively correlated. Note that the mean coefficients are of greater magnitude in the RPL models than in the standard logit. This is not surprising since a random parameter model decomposes the unobserved portion of utility and normalises parameters on the basis of part of the unobserved portions (Revelt and Train 1999).

\footnotetext{
${ }^{14}$ The restricted log likelihood is calculated with all coefficients set to zero.
} 
In Table 4 below we summarise the heterogeneity of the two models. Since the parameters are normally distributed some individuals will have an unexpected sign of the parameters. That some individuals have a negative value of the composite good might not be as strange as it seems, although the number of responses with a negative value is admittedly high. The reason for this is that some of the respondents do not like some of the improvements, most likely the environmental effect. Several respondents reacted against this in the open-ended question at the end of the survey; some argued that "green electricity" is not realistic, and some argued that they as passengers should not pay for the environmental effects that the modes cause.

Table 4. Illustration of the heterogeneity.

\begin{tabular}{|c|c|c|c|c|c|c|c|}
\hline & \multicolumn{4}{|c|}{ RPL without correlation } & \multicolumn{3}{|c|}{ RPL with correlation } \\
\hline & Mean & Coeff. std. & $\begin{array}{l}\text { Prob. } \\
\text { sign }\end{array}$ & reversed & Mean & Coeff. std. & $\begin{array}{l}\text { Prob. reversed } \\
\text { sign }\end{array}$ \\
\hline \multicolumn{8}{|l|}{ Constant: } \\
\hline$-\mathrm{X} 2000$ & 1.417 & 2.050 & & 0.25 & 1.272 & 3.363 & 0.35 \\
\hline - Arlanda & -0.656 & 1.910 & & 0.37 & -3.308 & 10.742 & 0.38 \\
\hline - Bromma & 0.031 & 2.697 & & 0.50 & -2.622 & 8.833 & 0.38 \\
\hline \multicolumn{8}{|l|}{ Composite: } \\
\hline - Rail & 1.028 & 1.158 & & 0.19 & 1.631 & 1.784 & 0.18 \\
\hline - Air & 1.836 & 1.595 & & 0.12 & 2.141 & 1.944 & 0.14 \\
\hline \multicolumn{8}{|l|}{ Time: } \\
\hline - Rail & -62.431 & 15.949 & & 0.00 & -89.549 & 63.900 & 0.08 \\
\hline - Air & -54.441 & 12.947 & & 0.00 & -66.858 & 49.313 & 0.09 \\
\hline Inertia & 7.507 & 0.498 & & 0.00 & 8.664 & 0.82 & 0.00 \\
\hline \multicolumn{8}{|l|}{ Out: } \\
\hline - X2000 & -1.470 & 0.625 & & 0.01 & -1.918 & 1.982 & 0.17 \\
\hline - Arlanda & -0.936 & 0.832 & & 0.13 & -1.290 & 2.499 & 0.30 \\
\hline - Bromma & -2.338 & 0.996 & & 0.01 & -2.906 & 2.647 & 0.14 \\
\hline
\end{tabular}

Based on the estimations above we can calculate the fare equivalents for the composite goods, and the value of time. The distribution of the mean estimates is obtained by the Krinsky-Robb method using 10,000 replications. The interesting question is to see if there is any significant difference in the estimates of the fare equivalents between the econometric models, and furthermore to compare the result of the primary experiment with the secondary experiments. 
Table 5. Fare equivalents in SEK for composite good and time, standard errors in parenthesis.

\begin{tabular}{|c|c|c|c|c|}
\hline & Secondary & Primary & & \\
\hline & & Standard logit & $\begin{array}{l}\text { RPL without } \\
\text { correlation }\end{array}$ & $\begin{array}{l}\text { RPL with } \\
\text { correlation }\end{array}$ \\
\hline Composite Rail & $\begin{array}{r}294.34 \\
(44.85)\end{array}$ & $\begin{array}{r}353.54 \\
(61.77)\end{array}$ & $\begin{array}{r}316.34 \\
(57.04)\end{array}$ & $\begin{array}{r}417.66 \\
(85.47)\end{array}$ \\
\hline Composite Air & $\begin{array}{r}530.46 \\
(110.79)\end{array}$ & $\begin{array}{r}570.99 \\
(61.02)\end{array}$ & $\begin{array}{r}564.88 \\
(59.28)\end{array}$ & $\begin{array}{l}548.26 \\
(83.54)\end{array}$ \\
\hline Value-of-time Rail & & $\begin{array}{r}18.19 \\
(2.48)\end{array}$ & $\begin{array}{r}19.21 \\
(3.12)\end{array}$ & $\begin{array}{l}22.93 \\
(2.27)\end{array}$ \\
\hline Value-of-time Air & & $\begin{array}{r}15.88 \\
(1.75)\end{array}$ & $\begin{array}{r}16.74 \\
(2.28)\end{array}$ & $\begin{array}{r}17.12 \\
(1.63)\end{array}$ \\
\hline
\end{tabular}

From Table 5 we see that there are some, non-significant, differences between a standard logit and the RPL models, but there is no consistent pattern. The value-of-time is higher for the RPL models, but there is no significant difference. The total fare equivalents for the composite good are higher in the primary experiments than in the secondary experiments for all econometric specifications. The result is surprising, since we would have expected the opposite result because of diminishing returns of the attributes. For example Kroes and Sheldon (1988), using a similar construction of the survey, find that the total fare equivalents are higher in the secondary experiments compared with the primary experiment. However, using the above result we could decompose the total fare equivalents using the result from the secondary experiments.

The value of time is expressed in SEK per minute. These values are extremely high in comparison to the results in other studies, e.g. the national Swedish value of time study (Algers et al. 1995), and the official values-of-time: $150 \mathrm{SEK} /$ hour for air business travel and 140/hour SEK for rail business travel. However, we must keep in mind that for the passengers in this survey the employer pays for the ticket. First of all we note that most of the passengers make their decisions about the mode themselves, although they may to some extent be governed by company rules. Second, we asked the respondents to answer the questions given the circumstances of the trip that they were undertaking. Therefore, the responses could still reflect the preferences of the company. As we discussed earlier, there is of course a risk that when the decision is delegated to the agents, there is a tendency to have a more lax budget restriction. In addition it is difficult to compare our result with the official value-of-time measures for business passengers, since the latter are based on a different approach, where the value of time is related to both the employer's value of time and the employee's value of time. Here we 
have only measured the employee's value of time, given the delegation mechanism where the employee make the decisions but does not have to bear the direct travel cost.

\section{Conclusions}

We find that business passengers put a substantial value on improvements of the environmental impact from the transport sector. The environmental improvements in the survey are not directly comparable, but the passengers value the environmental improvement from aviation more highly than the improvement from rail. Of the socalled secondary attributes, the environmental impact is the most important attribute for air travel, while environmental impact and reliability are of equal importance for rail travel. The values the business passengers put on the attributes are very high. One explanation for this is the fact that business passengers do not pay for the ticket themselves, thus they tend to ignore the price attribute in the survey. At the same time, most of the passengers make their trip decisions themselves. Since the passengers do not bear the direct cost of the trip this implies that the price attribute is of less importance, especially compared to costs that are borne by the passengers such as time, reliability and comfort. Therefore it seems important to define clearly whose values we are measuring, how we measure them and whose values we wish to measure.

The estimations show that a random parameter model in several aspects performs better than a fixed effect model, since it allows for heterogeneity. In this particular case we find a significant heterogeneity within the sample. However, the differences in fare equivalents between the models are not significant, and there is no consistent pattern of the differences. Our result conforms to the results of some other studies. For example, Train (1998) finds that the willingness-to-pay (WTP) for various fishing site attributes does not differ between a standard logit and an RPL. Revelt and Train (1999) find significant differences in WTP for some attributes while no differences for others. Train (1998) also reports the results of Bhat $(1996 a, b)$ who in one case finds no differences in the valuation of travel attributes between a standard logit and an RPL model, while in the other case finds significant differences. On the other hand, Algers et al. (1998) finds significant differences in the value of time between a standard logit and different RPL models, investigating long-distance car trips. In general, a comparison between a standard logit and a random specification depends, of course, on the data. It is thus 
difficult to judge whether a standard logit model provides reliable estimates without comparing it with an RPL model. 


\section{References}

Aghion, P. and J. Tirole (1997), 'Formal and real authority in organizations' Journal of Political Economy 105, 1-29.

Algers, S., B. Hugosson and J. Lindqvist Dillén (1995), 1994 års tidsvärdesstudie, Stockholm: Transek Consultancy.

Algers, S., P. Bergström, M. Dahlberg and J. Lindqvist Dillén (1998), 'Mixed logit estimation of the value of travel time', Working Paper 1998:15, Department of Economics, Uppsala University.

Allenby, G. and J. Ginter (1995), 'The effects of in-store displays and feature advertising on consideration sets', International Journal of Research in Marketing 12, 67-80.

Ben-Akiva, M. and T. Morikawa (1990), 'Estimation of travel demand models from multiple data sources', in Koshi, M. (ed.), Transportation and Traffic Theory, New York: Elsevier.

Bhat, C. (1995), 'A heteroskedastic extreme value model of intercity travel mode choice', Transportation Research B 29, 471-483.

Bhat, C. (1996a), 'Accommodating variations in responsiveness to level-of-service measures in travel mode choice modelling', Working Paper, Department of Civil Engineering, University of Massachusetts, Amherst.

Bhat, C. (1996b), 'Incorporating observed and unobserved heterogeneity in urban work travel choice modelling, Working Paper, Department of Civil Engineering, University of Massachusetts, Amherst.

Bhat C. (1997), 'Covariance heterogeneity in nested logit models: Econometric structure and application to intercity travel', Transportation Research B 31, 11-21.

Boyd, J. and R. Mellman (1980), 'The effect of fuel economy standards on the U.S. automotive market: A hedonic demand analysis', Transportation Research 14A, 367378.

Bradley, M. and Daly, A. (1997), 'Estimation of logit choice models using mixed stated-preference and revealed-preference information', in Stopher, P. and M. LeeGosselin (eds.), Understanding Travel Behaviour in an Era of Change, Oxford: Pergamon. 
Brownstone, D. and K. Train (1996), 'Forecasting new product penetration with flexible substitution patterns', Paper presented at American Economic Association Meetings, New Orleans.

Cardell, N. and F. Dunbar (1980), 'Measuring the societal impacts of automobile downsizing' Transportation Research 14A, 423-434.

Chen, H. and S. Cosslett (1998), 'Environmental quality preference and benefit estimation in multinomial probit models: A simulation approach', American Journal of Agricultural Economics 80, 512-520.

Fowkes, T., P. Marks and C. Nash (1991), 'Business travel', in Fowkes, T. and C. Nash (eds.), Analysing Demand for Rail Travel, Aldershot: Avebury.

Hausman, J. and D. Wise (1978), 'A conditional probit model for qualitative choice: Discrete decisions recognizing interdependence and heterogeneous preferences', Econometrica 46, 403-426.

Hajivassiliou, V. (1993), 'Simulation estimation methods for limited dependent variable models', in Maddala, G. Rao, C. and H. Vinod (eds.), Handbook of Statistics vol. 11, Amsterdam: Elsevier Science Publishers.

Hensher, D. (1994), 'Stated preference analysis of travel choices: The state of practice' Transportation 21, 107-133.

Hensher, D. and J. King (1998), 'Establishing fare elasticity regimes for urban passenger transport: Time-based fares for concession and non-concession markets segmented by trip length', Journal of Transportation and Logistics 1, 43-62.

Kling, C. (1991), 'Estimating the precision of welfare measures', Journal of Environmental Economics and Management 21, 244-259.

Krinsky, I. and A. Robb (1986), 'On approximating the statistical properties of elasticities', Review of Economics and Statistics 68, 715-719.

Kroes, E. and R. Sheldon (1988), 'Are there any limits to the amount consumers are prepared to pay for product improvements?', Paper presented at PTRC SAM 1988.

Lindqvist Dillén, J. and S. Algers (1998), 'Further research on the national Swedish value of time study', Paper presented at Economics and Institutions of Transport in Borlänge, May 25-27 1998. 
Louviere, J. (1984), 'Hierarchical information integration: A new method for the design and analysis of complex multiattribute judgement problems', in Kinnear, T. (ed.) Advances in Consumer Research 11, 148-155.

Louviere, J. and H. Timmermans (1990), 'Hierarchical information integration applied to residential choice behaviour', Geographical Analysis 22, 127-144.

McFadden, D. (1974), 'Conditional logit analysis of qualitative choice behaviour', in Zarembka, P. (ed.), Frontiers in Econometrics, New York: Academic Press.

McFadden, D. and K. Train (1998), 'Mixed MNL models for discrete response', Working paper, Department of Economics, University of California, Berkley.

Polak, J. and P. Jones (1997), 'Using stated-preference methods to examine traveller preferences and responses', in Stopher, P. and M. Lee-Gosselin (eds.), Understanding Travel Behaviour in an Era of Change, Oxford: Pergamon.

Revelt, D. and K. Train (1999), 'Mixed logit with repeated choices: Households' choices of appliance efficiency level', Review of Economics and Statistics, forthcoming.

Train, K. (1998), 'Recreation demand models with taste differences over people', Land Economics 74, 230-239. 


\section{Appendix}

Table A1. Attributes and levels for secondary experiments.

\begin{tabular}{|l|l|r|r|r|r|}
\hline Mode & Version & Environment & Reliability & Comfort & Increased Price \\
\hline Rail & I & Same as today & $90 \%$ on time & Same as today & +25 \\
& & Only green & $95 \%$ on time & Improved & +75 \\
\cline { 2 - 6 } & II & Same as today & $90 \%$ on time & Same as today & +20 \\
& & Only green & $95 \%$ on time & Improved & +90 \\
\hline Air & I & Same as today & $90 \%$ on time & Same as today & +75 \\
& & $40 \%$ reduction & $95 \%$ on time & Improved & +125 \\
\cline { 2 - 6 } & II & Same as today & $90 \%$ on time & Same as today & +50 \\
& & $40 \%$ reduction & $95 \%$ on time & Improved & +150 \\
\hline
\end{tabular}

Table A2. Attributes and levels for primary experiment

\begin{tabular}{|c|c|c|c|c|c|}
\hline \multirow[t]{2}{*}{ Mode } & \multicolumn{2}{|l|}{ Price } & \multicolumn{2}{|l|}{ Time } & \multirow{2}{*}{$\begin{array}{l}\text { Composite } \\
\text { factor }\end{array}$} \\
\hline & Rail pass. & Air pass. & Rail pass. & Air pass. & \\
\hline IC-train & $\begin{array}{r}250 \\
500 \\
650\end{array}$ & $\begin{array}{l}250 \\
500 \\
650\end{array}$ & $\begin{array}{l}3 \mathrm{~h} 55 \mathrm{~min} \\
4 \mathrm{~h} 20 \mathrm{~min}\end{array}$ & $\begin{array}{l}3 \mathrm{~h} 45 \mathrm{~min} \\
4 \mathrm{~h} 20 \mathrm{~min}\end{array}$ & $\begin{array}{l}0 \\
1\end{array}$ \\
\hline X2000-train & $\begin{array}{r}500 \\
750 \\
1100\end{array}$ & $\begin{array}{r}500 \\
750 \\
1100\end{array}$ & $\begin{array}{l}2 \text { h } 55 \text { min } \\
3 \text { h } 15 \text { min }\end{array}$ & $\begin{array}{l}2 \mathrm{~h} 40 \mathrm{~min} \\
3 \mathrm{~h} 10 \mathrm{~min}\end{array}$ & $\begin{array}{l}0 \\
1\end{array}$ \\
\hline Air Arlanda & $\begin{array}{r}800 \\
1000 \\
1200\end{array}$ & $\begin{array}{r}850 \\
1200 \\
1500\end{array}$ & $\begin{array}{l}1 \text { h } 50 \mathrm{~min} \\
2 \mathrm{~h} 25 \mathrm{~min}\end{array}$ & $\begin{array}{l}1 \text { h } 50 \mathrm{~min} \\
2 \mathrm{~h} 25 \mathrm{~min}\end{array}$ & $\begin{array}{l}0 \\
1\end{array}$ \\
\hline Air Bromma & $\begin{array}{r}800 \\
1000 \\
1200\end{array}$ & $\begin{array}{r}850 \\
1200 \\
1500\end{array}$ & $\begin{array}{r}1 \mathrm{~h} 25 \mathrm{~min} \\
2 \mathrm{~h}\end{array}$ & $\begin{array}{r}1 \mathrm{~h} 25 \mathrm{~min} \\
2 \mathrm{~h}\end{array}$ & $\begin{array}{l}0 \\
1\end{array}$ \\
\hline
\end{tabular}


Table A3. Cholesky factor of variance-covariance matrix and corresponding t-statistics.

Variance-covariance matrix:

\begin{tabular}{l|rrrrrrr|l} 
& $\begin{array}{l}\text { Con. } \\
\text { X2000 }\end{array}$ & $\begin{array}{l}\text { Con. } \\
\text { Arlanda }\end{array}$ & $\begin{array}{l}\text { Con. } \\
\text { Bromma }\end{array}$ & $\begin{array}{l}\text { Time } \\
\text { Train }\end{array}$ & $\begin{array}{l}\text { Time } \\
\text { Train }\end{array}$ & $\begin{array}{l}\text { Comp } \\
\text { Train }\end{array}$ & $\begin{array}{l}\text { Comp } \\
\text { Air }\end{array}$ & Variance \\
\hline Con. X2000 & 11.31 & & & & & & & \\
Con. Arlanda & 15.04 & 115.4 & & & & & \\
Con. Bromma & 11.99 & 91.14 & 78.016 & & & & \\
Time Train & -134.4 & -617.4 & -500.2 & 4083.2 & & & \\
Time Air & -150.6 & -214.6 & -194.2 & 1946.2 & 2431.8 & & \\
Comp. Train & 1.167 & -2.550 & -1.851 & 22.48 & -6.831 & 3.182 & \\
Comp. Air & 0.411 & -3.243 & -2.560 & 11.09 & -11.098 & 2.072 & 3.779 & \\
Inertia & & & & & & & & \\
Out X2000 & & & & & & & & \\
Out Arlanda & & & & & & & & \\
Out Bromma & & & & & & & & \\
\end{tabular}

t-statistics:

\begin{tabular}{l|rrrrrrr|l} 
& $\begin{array}{l}\text { Con. } \\
\text { X2000 }\end{array}$ & $\begin{array}{l}\text { Con. } \\
\text { Arlanda }\end{array}$ & $\begin{array}{l}\text { Con. } \\
\text { Bromma }\end{array}$ & $\begin{array}{l}\text { Time } \\
\text { Train }\end{array}$ & $\begin{array}{l}\text { Time } \\
\text { Train }\end{array}$ & $\begin{array}{l}\text { Comp } \\
\text { Train }\end{array}$ & $\begin{array}{l}\text { Comp } \\
\text { Air }\end{array}$ & Variance \\
\hline Con. X2000 & 1.991 & & & & & & & \\
Con. Arlanda & 1.107 & 2.687 & & & & & \\
Con. Bromma & 0.957 & 2.437 & 2.344 & & & & \\
Time Train & -1.826 & -2.746 & -2.421 & 3.146 & & & \\
Time Air & -2.730 & -1.430 & -1.321 & 2.233 & 2.661 & & \\
Comp. Train & 0.855 & -0.710 & -0.558 & 0.991 & -0.316 & 2.819 & \\
Comp. Air & 0.343 & -0.845 & -0.735 & 0.478 & -0.670 & 2.699 & 3.238 & \\
Inertia & & & & & & & & \\
Out X2000 & & & & & & & & \\
Out Arlanda & & & & & & & & \\
Out Bromma & & & & & & & & \\
\end{tabular}

